\title{
From bench to bedside: Can the improvements in left ventricular assist device design mitigate adverse events and increase survival?
}

\author{
Vincenzo Tarzia, MD, PhD, ${ }^{a}$ Gabriele Di Giammarco, $\mathrm{MD},{ }^{\mathrm{b}}$ Michele Di Mauro, MD, ${ }^{\mathrm{b}}$ \\ Giacomo Bortolussi, MD, ${ }^{\mathrm{a}}$ Massimo Maccherini, MD ${ }^{\mathrm{c}}$ Vincenzo Tursi, MD, ${ }^{\mathrm{d}}$ Massimo Maiani, MD, ${ }^{\mathrm{d}}$ \\ Sonia Bernazzali, MD, ${ }^{\mathrm{c}}$ Daniele Marinelli, MD, ${ }^{\mathrm{b}}$ Massimiliano Foschi, MD, ${ }^{\mathrm{b}}$ Edward Buratto, MBBS, ${ }^{\mathrm{a}}$ \\ Jonida Bejko, MD, ${ }^{\text {a }}$ Dario Gregori, MA, PhD, ${ }^{\text {a }}$ Silvia Scuri, Eng, PhD, ${ }^{a}$ Ugolino Livi, MD, ${ }^{\mathrm{d}}$ \\ Guido Sani, MD, ${ }^{\mathrm{c}}$ Tomaso Bottio, $\mathrm{MD}, \mathrm{PhD},{ }^{\mathrm{a}}$ and Gino Gerosa, $\mathrm{MD}^{\mathrm{a}}$
}

\section{ABSTRACT}

Objective: In vitro tests demonstrated that the new cone-bearing configuration of the Jarvik 2000 (Jarvik Heart Inc, New York, NY) left ventricular assist device exhibits better hydraulic efficiency than the previous pin-bearing design. We investigated the long-term outcomes of patients who received the Jarvik 2000 left ventricular assist device, depending on bearing design.

Methods: A retrospective review of prospectively collected data from 18 centers included in the Italian Registry was performed. From May 2008 to September 2013, 99 patients with end-stage heart failure were enrolled. Patients were divided into 2 groups according to their Jarvik 2000 suspending mechanism: Group pin included patients with pin bearings (May 2008 to June 2010), and group cone included patients with newer cone bearings (July 2010 to September 2013). The 2 groups did not differ significantly in terms of baseline characteristics.

Results: A total of 30 of 39 patients (group pin) and 46 of 60 patients (group cone) were discharged. During follow-up, 6 patients underwent transplantation, and in 1 patient the left ventricular assist device was explanted. The cumulative incidence competing risk of the entire cohort for noncardiovascular-related death was $28 \%$ (20\%-40\%); the cumulative incidence competing risk for cardiovascular-related death was 56\% (42\%-73\%): $71 \%$ in group pin versus $26 \%$ in group cone $(P=.034)$. The multivariate analyses confirmed that the pin-bearing design was a risk factor for cardiovascular death, along with Interagency Registry for Mechanically Assisted Circulatory Support class. Right ventricular failures and ischemic and hemorrhagic strokes were significantly higher in group pin.

Conclusions: Patients with the new pump configuration showed a better freedom from cardiovascular death and lower incidence of fatal stroke and right ventricular failure. Further studies are needed to prove the favorable impact of pump-enhanced fluid dynamics on long-term results. (J Thorac Cardiovasc Surg 2016;151:213-7)

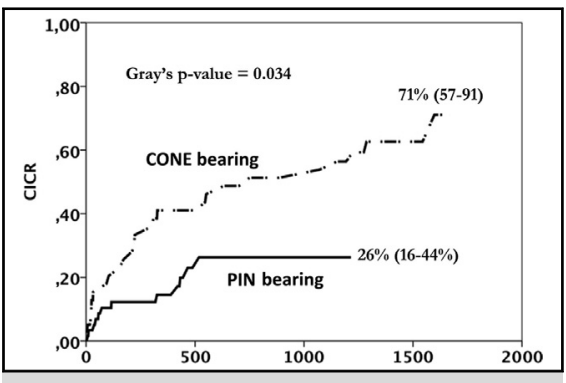

The CICR for CV death by bearing design: pin versus cone.

\section{Central Message}

Patients with the newer configuration of the Jarvik 2000 (Jarvik Heart Inc, New York, NY) LVAD showed a better freedom from CV death, stroke, and RV failure.

\section{Perspective}

In vitro tests demonstrated that the new conebearing configuration of the Jarvik 2000 LVAD exhibits better hydraulic efficiency than the previous pin-bearing design. We investigated in vivo the long-term outcomes of 99 patients with the Jarvik device who were enrolled in the Italian Registry. The new pump configuration was associated with less CV deaths and reduced complications.

See Editorial Commentary page 217.

See Editorials page 10 and 13.
In vitro experimental research is of vital importance because it allows new hypotheses to be piloted without experimentation on patients. Translational research is the

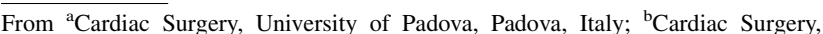
University of Chieti, Chieti, Italy; 'Cardiac Surgery, University of Siena, Siena, Italy; and ${ }^{\mathrm{d}}$ Cardiac Surgery, University of Udine, Udine, Italy.

Received for publication March 16, 2015; revisions received Aug 5, 2015; accepted for publication Sept 26, 2015; available ahead of print Nov 6, 2015.

Address for reprints: Vincenzo Tarzia, MD, PhD, Cardiac Surgery, Department of Cardiac, Thoracic and Vascular Sciences, University of Padova, Via Giustiniani 2, 35128 Padova, Italy (E-mail: v.tarzia@gmail.com). $0022-5223 / \$ 36.00$

Copyright (c) 2016 by The American Association for Thoracic Surgery http://dx.doi.org/10.1016/j.jtcvs.2015.09.107
}

step between promising in vitro results and their application to clinical practice. However, results determined in vitro often do not maintain their relevance when tested in real patients.

In the field of ventricular assist device technology, despite rapid progress in recent years, the search for the ideal device continues. ${ }^{1}$ An ideal device should have excellent hemodynamic performance, a low risk of thrombosis, a low risk of infection, and cause minimal patient inconvenience and discomfort. Because these are complex mechanical systems, much experimentation of new designs occurs in vitro before testing in the clinical setting. 


\section{Abbreviations and Acronyms}

CICR $=$ cumulative incidence competing risk

$\mathrm{CV}=$ cardiovascular

$\mathrm{LVAD}=$ left ventricular assist device

$\mathrm{RV} \quad=$ right ventricular

The Jarvik 2000 (Jarvik Heart Inc, New York, NY) is an axial flow ventricular assist device with an impeller pump supported by contact bearings. The original design of the Jarvik 2000 pump featured pin bearings to mount the impeller, but these were replaced with cone bearings in the latest design. ${ }^{2}$ The cone-bearing mechanism was developed for the pediatric model and tested in an animal model demonstrating a reduction in thrombus formation. $^{3,4}$ Therefore, it was introduced to the adult pump. Stanfield and Selzman ${ }^{5}$ demonstrated an improvement in hydrodynamic performance of the Jarvik 2000 because of this change in design when tested in vitro. However, at this stage there are only case reports comparing the 2 different suspension mechanisms in human patients. $^{6}$

We set out to investigate the impact of this modification on midterm outcomes in patients who underwent Jarvik 2000 implantation and were included in the Italian prospective multicenter national registry.

\section{MATERIALS AND METHODS \\ Patients and Groups}

A retrospective review of data concerning Jarvik 2000 implantation prospectively collected from 18 centers and included in the Italian Registry was performed. Written informed consent was obtained for all patients, and the study was approved by local institutional review boards.

From May 2008 to September 2013, 104 consecutive patients with end-stage heart failure were enrolled. Of these patients, 99 were adults and 5 were children, and the latter were excluded from the analysis. Patients were divided into 2 groups based on the design of their Jarvik 2000 suspension mechanism: Group pin included patients with pin bearings, implanted between May 2008 and June 2010; group cone included patients with newer cone bearings, implanted between July 2010 and September 2013. All patients were provided with the intermittent low-speed controller. Baseline demographic data for the 2 groups are shown in Table 1 . The patients in the 2 groups did not differ significantly in terms of baseline characteristics, although a tendency toward lower Interagency Registry for Mechanically Assisted Circulatory Support profile in group cone was observed.

\section{Surgical Technique}

The surgical technique used to implant the Jarvik 2000 device has been reported. ${ }^{7,8}$ In our series, surgical access was via left thoracotomy, sternotomy, and ministernotomy plus minithoracotomy in 71,20 , and 8 cases, respectively. In 62 patients, device implantation was performed off-pump, and in 35 cases cardiopulmonary bypass was used. The only differences found between groups were a higher rate of patients receiving the Jarvik 2000 device via median sternotomy (18 vs 2 ) or minimally invasive incision ( 8 vs 0 ) in the cone group.

\section{Follow-up and Outcome}

All discharged patients were closely followed up in outpatient clinics. The anticoagulation regimen was the same among centers, consisting of unfractionated heparin in the immediate postoperative period, followed by warfarin. The follow-up ended in December of 2013. The median interval time was 424 days (25th-75th percentiles: 220-777), with longer follow-up in group pin than in group cone $(737 \pm 506$ days vs $402 \pm 304$ days, $P<.001)$. The primary end point was the difference regarding cardiovascular (CV)-related deaths. The secondary outcomes were pump thrombosis, thrombotic and hemorrhagic cerebral and gastrointestinal deaths, and right ventricular (RV) failure.

\section{Statistical Analysis}

Differences between groups in independent, normally distributed, continuous variables were evaluated using the $t$ test. Variables that were not normally distributed were evaluated using the nonparametric Mann-Whitney $U$ test. Differences in categoric variables were evaluated using the Fisher exact test or Pearson's chi-square test for more than 2 groups. Cumulative incidence competing risk (CICR) was used to assess late outcome (deaths non-CV related; deaths CV related, transplants or explants). Difference between groups was assessed with Gray's test. ${ }^{9}$ The results are reported as CICR and $95 \%$ confidence interval. Hazard-proportional Cox analysis was performed to identify independent variables for lower freedom from CV deaths but undergoing transplantation or explantation. All the variables reported in Table 1 were initially included in the univariate analyses along with pin/cone-bearing pump design. In the initial multivariate models, we included all variables with a $P$ value less than .2 at univariate analysis. Center and cohort effects have been included in the model via a Gamma frailty. ${ }^{10}$ The internal validation of the model was performed using 1000 bootstrap samples. Finally, the model with the highest Harrell's C-index was reported. ${ }^{11}$ All comparisons were 2 -sided. We used the Statistical Package for the Social Sciences (IBM, Armonk, NY) and the R System.

\section{RESULTS \\ In-Hospital Mortality}

In-hospital mortality was $23 \%$ ( 23 cases); no difference between the 2 groups was found (9 [23\%] in group pin vs $14[23 \%]$ in group cone, $P=.976)$. Multiorgan failure was the main cause of death $(10 / 23,43 \%)$. Respiratory failure occurred in 4 patients $(17 \%)$, a hemorrhagic event occurred in 4 patients $(17 \%)$, and sepsis occurred in 3 patients (13\%); ischemic stroke and intestinal infarction occurred in 1 patient each.

\section{Survival}

Seventy-six patients were successfully discharged from the hospital, 30 with pin bearings and 46 with cone bearings. The baseline characteristics of the 2 groups are compared in Table 1. Among discharged patients, during follow-up 60 patients died of any cause (32 in group pin and 28 in group cone). A CV event was the cause of death in 37 of them ( 25 in group pin and 12 in group cone). There were 6 transplant recipients ( 5 in group cone vs 1 in group pin). In 1 case, the left ventricular assist device (LVAD) was explanted (group cone).

The CICR of the entire cohort for non-CV-related deaths was $28 \%(20 \%-40 \%)$. The CICR for CV-related deaths was $56 \%(42 \%-73 \%)$. The differences between groups 
TABLE 1. Preoperative patient characteristics by group

\begin{tabular}{|c|c|c|c|}
\hline Characteristic & $\begin{array}{c}\text { Group pin } \\
(\mathbf{n}=\mathbf{3 9})\end{array}$ & $\begin{array}{c}\text { Group cone } \\
\quad(\mathbf{n}=60)\end{array}$ & $P$ value \\
\hline \multicolumn{4}{|l|}{ Demographics } \\
\hline Age, y & $61 \pm 8.5$ & $61 \pm 9.3$ & .903 \\
\hline Male & $35(90)$ & $50(83)$ & .381 \\
\hline BSA, $m^{2}$ & $1.87 \pm 0.2$ & $1.83 \pm 0.2$ & .300 \\
\hline Cardiac status & & & .525 \\
\hline ICM & $22(56)$ & $28(47)$ & \\
\hline DCM & $15(38)$ & $29(48)$ & \\
\hline Other & $2(5)$ & $3(5)$ & \\
\hline LVEF (\%) & $22 \pm 5$ & $21 \pm 5.6$ & .378 \\
\hline INTERMACS & & & .062 \\
\hline 1 & $5(13)$ & $7(12)$ & \\
\hline 2 & $2(5)$ & $17(28)$ & \\
\hline 3 & $9(23)$ & $8(13)$ & \\
\hline 4 & $22(56)$ & $23(38)$ & \\
\hline 5 & $1(3)$ & $3(5)$ & \\
\hline Missing & 0 & $2(3)$ & \\
\hline \multicolumn{4}{|l|}{ Hemodynamics } \\
\hline Systolic BP, mm Hg & $100 \pm 9.2$ & $102 \pm 11.7$ & .585 \\
\hline Systolic PAP, mm Hg & $49 \pm 18.5$ & $53 \pm 15.5$ & .348 \\
\hline PCWP, mm Hg & $21 \pm 8.4$ & $25 \pm 8.8$ & .125 \\
\hline $\mathrm{CI}, \mathrm{L} / \mathrm{min} / \mathrm{m}^{2}$ & $2.0 \pm 0.5$ & $1.9 \pm 0.4$ & .684 \\
\hline \multicolumn{4}{|l|}{ Laboratory values } \\
\hline Creatinine, $\mathrm{mg} / \mathrm{dL}$ & $1.5 \pm 0.5$ & $1.5 \pm 0.6$ & .918 \\
\hline Bilirubin, $\mathrm{mg} / \mathrm{dL}$ & $1.1 \pm 0.5$ & $1.3 \pm 0.9$ & .365 \\
\hline Hemoglobin $\mathrm{mg} / \mathrm{dL}$ & $12.4 \pm 1.4$ & $11.7 \pm 1.8$ & .068 \\
\hline Platelets per $\mathrm{mm}^{3}$ & $210 \pm 74.6$ & $215 \pm 74.6$ & .790 \\
\hline \multicolumn{4}{|c|}{ Additional supportive therapies } \\
\hline ECMO & $2(5)$ & $4(7)$ & .754 \\
\hline IABP & $3(8)$ & $4(7)$ & .846 \\
\hline ICD & $22(56)$ & $54(90)$ & $<.001$ \\
\hline CVVH & $2(5)$ & $2(3)$ & .645 \\
\hline
\end{tabular}

$B S A$, Body surface area; $I C M$, ischemic cardiomyopathy; $D C M$, dilated cardiomyopathy; $L V E F$, left ventricular ejection fraction; INTERMACS, Interagency Registry for Mechanically Assisted Circulatory Support; BP, blood pressure; PAP, pulmonary artery pressure; $P C W P$, pulmonary capillary wedge pressure; $C I$, cardiac index; $E C M O$, extracorporeal membrane oxygenation; $I A B P$, intra-aortic balloon pump; $I C D$, implantable cardioverter defibrillator; $C V V H$, continuous veno-venous hemofiltration.

are plotted in Figures 1 and 2. CICR for transplanted or explanted LVAD was $8 \%(4 \%-18 \%)$ without a difference between groups (cone 16\% [7\%-36\%] vs pin 3\% $[0 \%-18 \%], P=.12$ ). The multivariate analyses confirmed that pin-bearing and Interagency Registry for Mechanically Assisted Circulatory Support class are risk factors for CV death, modeling center, and cohort of enrollment as frailty $(P<.05)$ to exclude the effect of different era of implant. Adjustment for center volume, age and gender of patients, and etiology was considered, but it was not significant (Table 2).

\section{Events}

The CICRs for some CV fatal events are summarized in Table 3. RV failures and ischemic and hemorrhagic strokes were significantly higher in group pin.

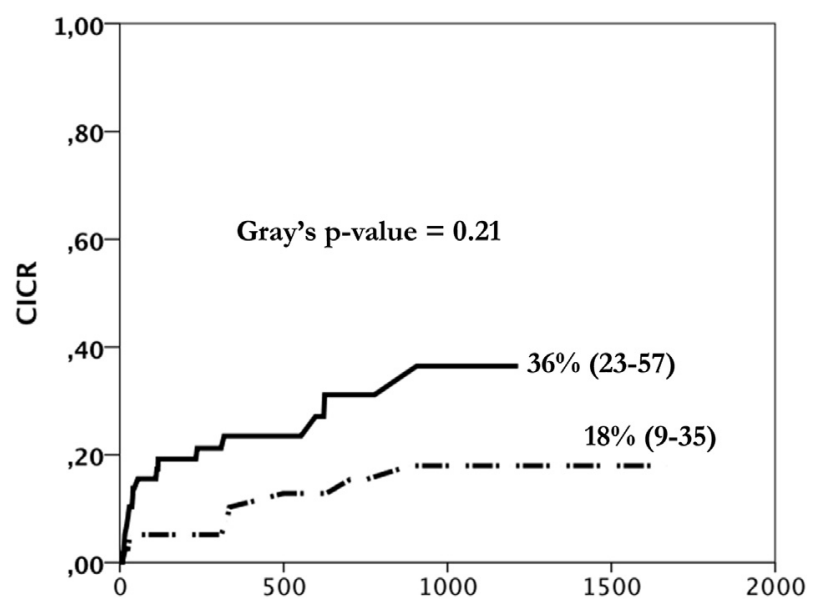

FIGURE 1. CICR for non-CV-related deaths by bearing design: pin (solid line) and cone (dashed line). CICR, Cumulative incidence competing risk.

\section{DISCUSSION}

The introduction of LVADs has generated major advances in the treatment of end-stage cardiomyopathies. ${ }^{12}$ However, major disadvantages associated with LVADs compared with heart transplantation remain, including the need for anticoagulation and the competing risks of thromboembolism and hemorrhage. Thus, pump designs are continually evolving to reduce that risk. The modification of bearing design in the Jarvik 2000 device represents one such improvement.

The original pin-bearing design was associated with a high risk of thrombosis, especially in the case of the pediatric size pump. ${ }^{2-4}$ An upgraded design in the form of cone bearings was developed and tested in the animal model, significantly reducing the risk of thrombosis. ${ }^{4}$ The same design was introduced in the pediatric model and later the adult model. This design recently has been shown to provide significant hydrodynamic improvement in vitro. ${ }^{5}$ However, no clinical evidence of the superiority of cone over pin-bearing design has been reported so far. This study aimed to assess whether the introduction of the cone-bearing design has provided any clinical improvement in patients' outcomes. This study is unique because it includes the largest cohort of patients supported with the Jarvik 2000 device reported so far.

The main finding of this retrospective clinical study was that the new bearing design (cone) is associated with improved CV-related survival, a finding confirmed with multivariate analysis. To better understand the reasons for this improved survival, $\mathrm{CV}$ events were also investigated: The risk of fatal ischemic or hemorrhagic stroke and late $\mathrm{RV}$ failure was significantly decreased with the new design.

The increased resistance of the cone-bearing design to thrombus formation around the suspending mechanism of the impeller under the same anticoagulation protocol could 


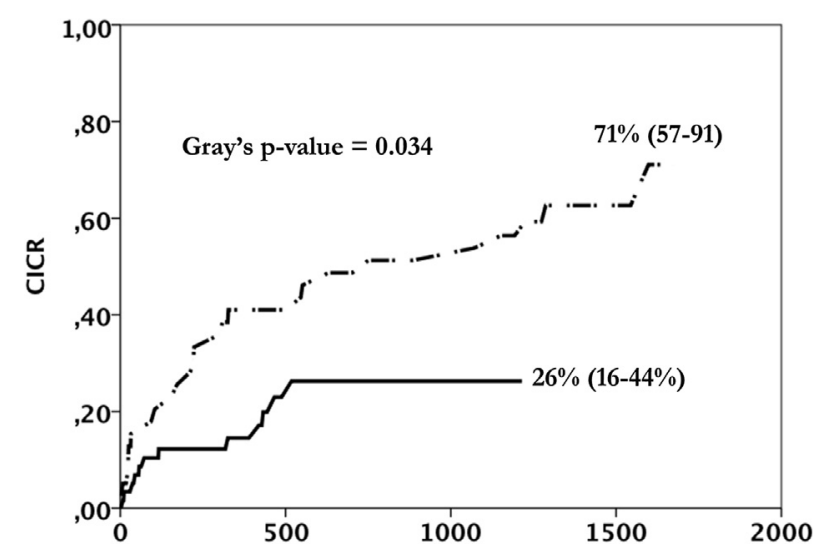

FIGURE 2. CICR for CV-related deaths by bearing design: pin (solid line) and cone (dashed line). CICR, Cumulative incidence competing risk.

explain the lower rate of thromboembolic complications recorded in our registry with the second-generation Jarvik 2000 device.

The reduction of hemorrhagic events in the same subset of patients is more difficult to justify, because it may be indirect. One suggestion could be the relationship found in the literature between increased hemolysis rate during pump thrombosis and an acquired von Willebrand syndrome. ${ }^{13-16}$ An additional pathophysiologic mechanism may be related to an increase in platelet consumption produced by thrombus formation with impairment of the hemostatic process and an associated increased risk of hemorrhagic stroke and gastrointestinal bleeding. The decrease in RV failure may be explained by the increased pump efficiency of the new Jarvik design with improved unloading of the RV. ${ }^{17}$

\section{Study Limitations}

The main limitation of this study is its retrospective nonrandomized design. Moreover, information regarding the coagulation state across the follow-up was not available in all patients. Finally, no information concerning RV function at discharge was recorded.

TABLE 2. Cox proportional model of risk factors for cardiovascular death

\begin{tabular}{|c|c|c|c|c|}
\hline \multirow[b]{2}{*}{ Risk factor } & \multirow[b]{2}{*}{ HR } & \multicolumn{2}{|c|}{$95 \% \mathrm{CI}$} & \multirow[b]{2}{*}{$P$ value } \\
\hline & & Lower & Upper & \\
\hline Pin & 2.70 & 1.30 & 5.79 & .01 \\
\hline INTERMACS & 0.58 & 0.41 & 0.83 & $<.001$ \\
\hline High-volume centers & 0.74 & 0.36 & 1.51 & .41 \\
\hline Age & 1.01 & 0.97 & 1.05 & .65 \\
\hline Female vs male & 1.91 & 0.70 & 5.21 & .21 \\
\hline Ischemic vs nonischemic $\mathrm{CM}$ & 1.18 & 0.57 & 2.45 & .66 \\
\hline
\end{tabular}

Harrell's C-index 0.70. HR, Hazard ratio; CI, confidence interval; INTERMACS, Interagency Registry for Mechanically Assisted Circulatory Support; $C M$, cardiomyopathy.
TABLE 3. Cumulative incidence competing risk for some cardiovascular fatal events

\begin{tabular}{lcc}
\hline \multicolumn{1}{c}{ Event } & Group pin $(\mathbf{n}=39)$ & Group cone $(\mathbf{n}=\mathbf{6 0})$ \\
\hline Right heart failures & $16 \%(7 \%-33 \%)$ & $6 \%(2 \%-17 \%)^{*}$ \\
Pump thrombosis & $5 \%(1 \%-18 \%)$ & $5 \%(1 \%-20 \%)$ \\
$\begin{array}{l}\text { Ischemic/hemorrhagic } \\
\quad \text { strokes }\end{array}$ & $39 \%(24 \%-63 \%)$ & $11 \%(5 \%-26 \%)^{*}$ \\
GI ischemic/hemorrhagic & $10 \%(4 \%-26 \%)$ & $3 \%(1 \%-14 \%)$ \\
$\quad$ events & & \\
GI, Gastrointestinal. $* P<.05$. &
\end{tabular}

\section{CONCLUSIONS}

The clinical outcomes after Jarvik 2000 LVAD implantation have been improved by the introduction of the cone-bearing design. There was a significant reduction in both hemorrhagic and ischemic stroke risk with the new design. Moreover, the new design provides a hemodynamic improvement with consequent reduction in the rate of RV failure. All of these advantages contribute to the significant improvement in freedom from $\mathrm{CV}$ death in our registry.

\section{Conflict of Interest Statement}

S.S. is a consultant for ArTech srl (dealer of biomedical products, including the Jarvik 2000). All other authors have nothing to disclose with regard to commercial support.

\section{References}

1. Patel CB, Cowger JA, Zuckermann A. A contemporary review of mechanical circulatory support. J Heart Lung Transplant. 2014;33:667-74.

2. Jarvik R. Jarvik 2000 pump technology and miniaturization. Heart Fail Clin. 2014;10:S27-38.

3. Kilic A, Nolan TD, Li T, Yankey GK, Prastein DJ, Cheng G, et al. Early in vivo experience with the pediatric Jarvik 2000 heart. ASAIO J. 2007; 53:374-8.

4. Gibber M, Wu ZJ, Chang WB, Bianchi G, Hu J, Garcia J, et al. In vivo experience of the child-size pediatric Jarvik 2000 heart: update. ASAIO J. 2010;56:369-76.

5. Stanfield JR, Selzman CH. In vitro hydrodynamic analysis of pin and cone bearing designs of the Jarvik 2000 adult ventricular assist device. Artif Organs. 2013;37:825-33.

6. Saito S, Sakaguchi T, Miyagawa S, Nishi H, Yoshikawa Y, Fukushima S, et al. Jarvik 2000 biventricular assist device conversion from old pin-shaped bearing pumps to new conical bearing pumps. J Artif Organs. 2013;16: 105-9.

7. Tarzia V, Buratto E, Dal Lin C, Gallo M, Bortolussi G, Bejko J, et al. Jarvik 2000: evolution of surgical implantation from conventional to minimally invasive technique. Ann Cardiothorac Surg. 2014;3:621-3.

8. Gerosa G, Gallo M, Tarzia V, Di Gregorio G, Zanella F, Bottio T. Less invasive surgical and perfusion technique for implantation of the Jarvik 2000 left ventricular assist device. Ann Thorac Surg. 2013;96:712-4.

9. Fine JP, Gray RJ. A proportional hazards model for the subdistribution of a competing risk. J Am Stat Assoc. 1999;94:496-509.

10. Therneau TM, Grambsch PM, Pankratz VS. Penalized survival models and frailty. J Comput Graph Stat. 2003;12:156-75.

11. Harrell FE, Lee KL, Mark DB. Multivariate prognostic models: issues in developing models, evaluating assumptions and adequacy, and measuring and reducing errors. Stat Med. 1996;15:361-87.

12. Kirklin JK, Naftel DC, Kormos RL, Stevenson LW, Pagani FD, Miller MA, et al. Fifth INTERMACS annual report: risk factor analysis from more than 6,000 
mechanical circulatory support patients. J Heart Lung Transplant. 2013;32: $141-56$.

13. Ravichandran AK, Parker J, Novak E, Joseph SM, Schilling JD, Ewald GA, et al. Hemolysis in left ventricular assist device: a retrospective analysis of outcomes. J Heart Lung Transplant. 2014;33:44-50.

14. Cowger JA, Romano MA, Shah P, Shah N, Mehta V, Haft JW, et al. Hemolysis: a harbinger of adverse outcome after left ventricular assist device implant. J Heart Lung Transplant. 2014;33:35-43.

15. Birschmann I, Dittrich M, Eller T, Wiegmann B, Reininger AJ, Budde U, et al. Ambient hemolysis and activation of coagulation is different between HeartMate II and HeartWare left ventricular assist devices. J Heart Lung Transplant. 2014; 33:80-7.
16. Tarzia V, Buratto E, Bortolussi G, Gallo M, Bejko J, Bianco R, et al Haemorrhage and thrombosis with different LVAD technologies: a matter of flow? Ann Cardiothorac Surg. 2014;3:582-4.

17. Kukucka M, Potapov E, Stepanenko A, Weller K, Mladenow A, Kuppe H, et al Acute impact of left ventricular unloading by left ventricular assist device on the right ventricle geometry and function: effect of nitric oxide inhalation. $J$ Thorac Cardiovasc Surg. 2011;141:1009-14.

Key Words: ventricular assist device, LVAD, Jarvik 2000, bearing system, heart failure, follow-up

\title{
EDITORIAL COMMENTARY
}

\section{Coning down on the effects of an left ventricular assist device engineering enhancement}

\author{
Ming-Sing Si, MD
}

From the Department of Cardiac Surgery, Section of Pediatric Cardiovascular Surgery, University of Michigan, Ann Arbor, Mich.

Disclosures: Author has nothing to disclose with regard to commercial support.

Received for publication Oct 7, 2015; accepted for publication Oct 7, 2015.

Address for reprints: Ming-Sing Si, MD, Department of Cardiac Surgery, University of Michigan, Section of Pe-

diatric Cardiovascular Surgery, 11-735 C. S. Mott Children's Hospital, SPC 4204, 1540 E Hospital Dr, Ann

Arbor, MI 48109-4204 (E-mail: mingsing@umich.edu).

J Thorac Cardiovasc Surg 2016;151:217-8

$0022-5223 / \$ 36.00$

Copyright (C) 2016 by The American Association for Thoracic Surgery

http://dx.doi.org/10.1016/j.jtcvs.2015.10.030

Left ventricular assist devices (LVADs) represent one of the quintessential engineering accomplishments that have improved the quantity and quality of life for patients with end-stage heart failure. Although the primary function of LVADs is to augment or replace native cardiac output, they also have strict engineering requirements related to minimization of size, ease of implantability, and interaction with the hematologic system. These challenges have been continuously addressed during the relatively short history of the various LVADs available for clinical use.

In this issue of the Journal, a study by Tarzia and colleagues ${ }^{1}$ highlights the midterm clinical effects of a design change in the Jarvik 2000 LVAD (Jarvik Heart, Inc, New York, NY). The iterative improvement of this axial-flow device is centered on the bearing design: the first generation used a pin and sleeve configuration, whereas the newer generation device uses a cone and seat design. In this retrospective study, the investigators used the Italian registry to identify 99 cases of patients who received the Jarvik 2000 LVAD in a 5 -year period. Because the study time frame

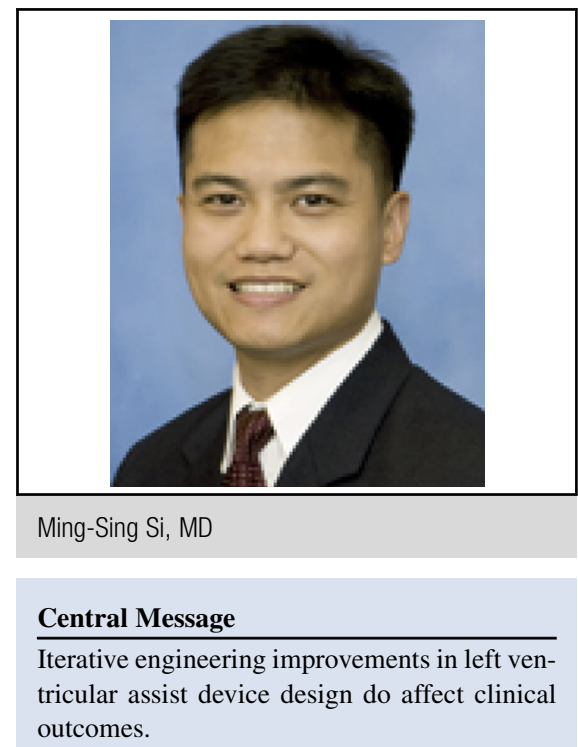

See Article page 213.

See Editorials page 10 and 13.

straddled the change in bearing design, 2 distinct groups of patients, derived from the era of implantation, were compared. The 2 groups had similar baseline characteristics. By applying various statistical methods, Tarzia and colleagues ${ }^{1}$ found that the group of patients who had received the device with the newer cone bearing design had significantly lower rates of cardiovascular-related death, 